\title{
14
}

\section{QUE CIVILIZAÇÃO IMPORTA NO EXTREMO DO MUNDO: A SÉRIE THE TERROR}

Daniel Soares Duarte

Recebido em 21 fev 2021. Daniel Soares Duarte

Aprovado em 18 abr 2021. Doutor em Letras pela Universidade Federal de Santa Catarina (2012), na área de Teoria da Literatura, com pesquisa sobre a poesia de Carlos Drummond de Andrade e a teoria dos sistemas.

Professor do Bacharelado em Tradução InglêsPortuguês da Universidade Federal de Pelotas.

http://lattes.cnpq.br/0379645695998422

danisoaresduarte@gmail.com

http://orcid.org/0000-0002-8453-5701

Resumo: este artigo tem como objetivo discutir alguns valores relativos à ideia de "civilização" a partir de eventos mostrados na série The Terror, atualmente disponível na plataforma de streaming Amazon Prime Video. A série apresenta uma constante luta entre valores, sempre implícita nas ações das personagens: manutenção de hierarquia, o embate entre o que é considerado inferior e superior, a noção enganosa de superioridade frente à natureza, entre outros. A narrativa gira em torno da chamada Expedição Franklin, uma tentativa da Inglaterra, em 1845, de alcançar a China, não fazendo a volta da costa africana, mas passando pelo norte do Canadá, no círculo polar ártico. Algumas ideias aqui apresentadas dialogam com a investigação de Keith Thomas (1988) acerca da 
presunção ocidental de domínio da natureza para a demonstração de uma "civilização", noção implícita em todas as cenas da série citada e que dialoga com a obra de Norbert Elias (1990). São essas questões sobre o embate entre o desejo civilizatório e as pulsões e a rudeza natural e humana que propiciam 0 desenvolvimento dos sentimentos de horror e terror (CAVALLARO, 2002). No presente texto, no entanto, as ideias de Elias são também interpretadas por Jessé Souza (2000) sobre como os valores civilizados entram em embate com uma ideologia de subjugação, bem como com a expansão do processo civilizador.

Palavras-chave: Processo Civilizador. The Terror. Natureza. Ficção.

Abstract: this article aims at discussing values related to the idea of "civilization" based on events shown in the series The Terror, currently available on the streaming platform Amazon Prime Video. The series presents a constant struggle between values that are always implicit in the characters' actions: the maintenance of hierarchy, the clash between what is considered inferior and superior, the misleading notion of superiority over nature, among others. The narrative revolves around the socalled Franklin Expedition, an attempt by England, in 1845 , to reach China, not by going around the African coast, but passing through northern Canada, in the Arctic Circle. Some ideas presented here converse with Keith Thomas' (1988) investigation of the Western assumption of mastering nature for the demonstration of a "civilization", a notion implicit in all scenes of the series, and that dialogue with the work of Norbert Elias (1990). It is these questions about the clash between the civilizing desire and the natural and human drives and rudeness that provide the development of feelings of horror and terror (CAVALLARO, 2002). In the present text, Elias' ideas are interpreted by Jessé Souza (2000) on how 
civilized values clash with an ideology of perversion and subjugation, as well as with the expansion of the civilizing process.

Keywords: Civilizing Process. The Terror. Nature. Fiction.

\section{INTRODUÇÃO}

Este texto tem como objetivo discutir a imbricação do tema do processo civilizatório e como ele conversa com a emergência de dois sentimentos distintos, porém imbricados (terror e horror) na série The Terror, atualmente em exibição no Brasil pela plataforma de streaming Amazon Prime Video. No que se segue, apresentarei brevemente a série, alguns dos seus desenvolvimentos narrativos e temas, partindo da narrativa para tratar dos temas. Trato em seguida dos temas do processo civilizatório, conforme concebidos por Norbert Elias (1990), e relacionando-os com o surgimento e o desenvolvimento dos sentimentos de terror e horror em exemplos da série. Podemos, sem ainda indicá-lo, inicialmente considerar o processo civilizatório como "tudo aquilo em relação a que a sociedade ocidental explicita sua autenticidade e singularidade e, acima de tudo, tudo aquilo em relação a que o Ocidente 'se orgulha'” (SOUZA, 2009, p. 43). Não se trata de um processo sem ambiguidade; ao contrário, constitui-se a partir da supressão organizada, porém sempre incompleta, de tudo o que lembra a animalidade. Tudo o que pertence ao que é natural, em especial as expansões sentimentais e pulsionais, como o sexo, a catarse, as emoções inferiores, deve ser primeiro suprimido e depois racionalizado. Especificamente, Elias indica três aspectos: autocontrole ("o controle efetuado através de terceiras pessoas 
é convertido, de vários aspectos, em autocontrole"), exclusão da animalidade ("as atividades humanas mais animalescas são progressivamente excluídas do palco da vida comunal e investidas de sentimentos de vergonha"), e estabilidade ("a regulação de toda a vida instintiva e afetiva por um firme autocontrole se torna cada vez mais estável, uniforme e generalizada") (ELIAS, 1990, p. 193-194). Como corolário, civilização seria também tudo o que é sinônimo de conquista da natureza (THOMAS, 1988, p. 31). Entendo que essa dialética entre o mundo natural e o mundo civilizado, ou melhor, entre a ideia de um mundo civilizado e a de um mundo natural, está no centro das ações da série The Terror. $\mathrm{E}$ domínio, tanto em sentido de controle quanto de supressão, é um elemento-chave no desenvolvimento da história.

Minha análise se detém na primeira temporada. A série propõe temporadas em arcos narrativos fechados. A primeira é baseada no romance homônimo de Dan Simmons (2007), e ficcionaliza os eventos que levaram ao fracasso total da chamada Expedição Franklin, uma empreitada feita por dois navios, HMS Erebus e HMS Terror (de onde se origina o nome tanto do romance quanto da série), na expedição capitaneada por John Franklin, explorador do ártico, após o inverno de 1846 (um ano após o início da expedição), quando os mesmos foram vistos na llha Beechey, extremo norte do Canadá. O desaparecimento dos dois navios levou a sucessivas expedições de busca (TURNER, 2001), infrutíferas. A expedição tornou-se uma narrativa lendária e de bastante fama na história da exploração do ártico (ver BEATTIE; GEIGER, 2014; DAVIS-FISCH, 2012, e OFFICER; PAGE, 2012 - além de uma lista de documentários sobre o assunto em POTTER, 
2018), e os navios somente foram descobertos a partir de 2014, em investigações que usaram tecnologia mais avançada para revelá-los. Segundo o depoimento do escritor Fergus Fleming,

a procura por Franklin foi uma das maiores buscas já organizadas na história. O almirantado ofereceu uma série de prêmios. 20.000 libras para quem encontrasse o próprio Franklin, 10.000 para quem encontrasse seus navios. Em uma temporada havia nada menos que 13 navios espalhados pelo Ártico tentando encontrar Franklin. ${ }^{1}$ (TURNER, 2001, 41:27²)

Dado o mistério envolvendo o destino da expedição, foi possível ficcionalizar a narrativa. Não obstante, muito dela apresenta elementos factuais que foram revelados ao longo do tempo e em parte esclarecidos pela descoberta dos navios afundados, em 2014. Detalhes que não diminuíram o mistério e em parte o aumentaram: uma mensagem de Franklin, deixada em papel dentro de uma lata, em um monte de pedras numa ilha remota, afirmando que tudo estava bem, com correções posteriores (dois anos mais tarde) feitas pelos capitães Francis Crozier e James Fitzjames, dizendo que Franklin havia morrido dois dias depois de deixar a mensagem; evidências de separação em grupos e suposições de motins, suspeitas de canibalismo e, com mais evidências, uma provável lenta contaminação por chumbo em toda a tripulação dos navios a partir das latas em conserva

1 Tradução minha de "The search for Franklin was one of the biggest organized man hunts in history. The Admiralty offered a series of prizes. There was 20,000 pounds for finding Franklin himself, 10,000 pounds for finding his ships. In one season there were no less than 13 ships swarming all over the Arctic trying to find Franklin".

2 O documentário está disponível em: https://www.youtube.com/watch?v=j94t4tN1w0\&t=2510s. Acesso em: 15 fev. 2021. 
usadas na comida, consumida por cerca de quatro anos seguidos. Comida em latas era uma inovadora tecnologia da época (18451848), que provou-se um elemento desastroso na expedição (TURNER, 2001).

A série assim se embasa em descobertas factuais, mas extrapola e usa as lacunas narrativas e históricas para criar um universo em que o horror e o terror compõem e de algum modo encapsulam a experiência das personagens. Os dois termos têm validade aqui. Segundo Dani Cavallaro, em sua introdução ao tema:

O modelo teórico baseado na oposição entre terror e horror provou-se influente: terror é considerado tudo o que é intangivel e resiste a definição; horror é definido em virtude de sua natureza material. David Punter descreve a oposição da seguinte forma: o terror denota "o tremor, o limiar, a sensação de espera", bem como "uma implicação ilimitada do eu em uma série de ações que nos convencem de sua inexorabilidade", enquanto o horror "é um olhar transfixado" que "nos proporciona choque e surpresa" (PUNTER, 1998, p. 236-7). De acordo com esse modelo, os poderes inquietantes do horror estão ligados a objetos identificáveis, principalmente o corpo, e a perturbações visíveis da ordem natural que causam reações físicas intensas. [...] O terror, ao contrário, perturba pela indeterminação: não é possível vinculá-lo a um objeto físico identificável nem é possível classificar ou nomear os fatores que o determinam. ${ }^{3}$ (2002, p. 2, grifo meu)

3 Tradução minha de "The theoretical model based on the opposition between terror and horror has proved especially influential, terror deemed intangible and resistant to definition, horror definable by virtue of its material nature. David Punter outlines the opposition as follows: terror denotes the 'trembling, the liminal, the sense of waiting' as well as 'a limitless implication of the self in a series of actions which persuade us of their inexorability', whereas horror 'is a stark transfixed staring' which 'provides us with shock and surprise' (1998:236-7). According to this model, the unsettling 
A distinção entre horror e terror é útil nesse caso para afirmar como ambos estão presentes na narrativa. A montagem da série explora tanto a vivência do horror às ameaças físicas no extremo do mundo quanto o terror advindo dos sentimentos e intuições das personagens. Minha hipótese aqui é de que tais sentimentos e vivências ocorrem em situações que colocam em choque valores civilizacionais e práticas que demonstram a brutalidade humana, seja natural ou cultivada.

\section{TERROR E CIVILIZAÇÃO}

O embate entre 1) a ideia de civilização e as forças 2) naturais e 3) sobrenaturais acontece em todos os momentos da série, e várias são as ocorrências mostradas: 1) a punição contra amotinados e insubordinados; a descoberta gradual de que a comida enlatada está sendo contaminada por chumbo presente nas latas, desde o início da expedição, causando dores, alucinação e loucura na tripulação; a morte acidental de um xamã netsilik e o preconceito contra a presença da filha dele a bordo; motins; uma tentativa de festa que acaba em incêndio e pandemônio; um capitão alcoólatra; 2) cenas gráficas de canibalismo e cirurgias sem anestesia; um tripulante que sofre um acidente, perde parte do crânio mas continua vivo, embora em coma; 3) o ataque de um "monstro" (chamado de Toonbaq ou Tuun'aq) considerado mítico pela cultura local, os netsiliks; 4) medo de fantasmas, etc. Por brevidade, vou me deter em dois exemplos que se desenvolvem

powers of horror are linked to identifiable objects, most notably the body, and to visible disruptions of the natural order which cause intensely physical reactions. [...] Terror, conversely, disturbs because of its indeterminateness: it cannot be connected with an identifiable physical object and the factors that determine it accordingly elude classification and naming. 
pela série inteira: i) o uso que o capitão Crozier, comandante do Terror, faz do exercício de autoridade e do terror, como um bastião que aponta sempre para os valores da civilização e faz a mediação do uso da força e da violência como dispositivo legitimador, e ii) como as ações do "monstro" que ataca os navios ressoam em nossos valores ainda ativos (apesar de implícitos) de cultura, civilização e natureza, por conter características mais próximas de um horror cósmico (RALICKAS, 2007, p. 364).

No final do terceiro episódio, "The Ladder", Sir John Franklin, líder da expedição, é morto pelo monstro (Toonbaq ou Tuun’aq, a se usar a pronúncia inglesa ou tanuktitut), que ataca de surpresa uma guarnição que esperava capturá-lo. No início do quarto episódio, "Punished, as a Boy", o monstro demonstra argúcia sobre-humana: "monta" um corpo com duas partes de homens que havia matado e o coloca de pé sobre o navio. A aparência do monstro vai sendo revelada aos poucos, ao longo dos episódios, lembrando a de um urso polar com o dobro do tamanho, mas com uma cabeça quase humanoide. Alguns homens, entre eles o marujo Cornelius Hickey, decidem capturar a filha do xamã morto, crendo que ela saberá explicar a natureza da criatura e atraí-la. Fazem isso à revelia das ordens de Crozier, capitão do Terror. Quando este descobre, decide puni-los, por insubordinação e por envergonhar a mulher. Hickey diz que o grupo viu a criatura junto a ela, que os dois se comunicavam, e desafia a autoridade de Crozier quando este distribui as punições por desobediência: doze chibatadas. Como Hickey fica mais e mais impertinente, Crozier aumenta o número para trinta, apenas para ele. Hickey diz que na verdade salvou a vida de Crozier trazendo a mulher; os tons de voz 
se elevam e o capitão ordena, furioso, porém contido, desafiando Hickey (32:574): "Tenente Little, diga ao sr. Jonhson que o sr. Hickey será punido como um menino". Há um corte súbito com uma voz em off com bater de um bumbo: "Todas as mãos prontas para o castigo". Um marujo pergunta: "Vai doer?" Outro responde: "Sim, Manson. Esse é o objetivo". Ser punido como um menino, a cena mostra, é ser preso a uma mesa para levar as chibatadas não nas costas nuas, mas nas nádegas. Hickey é amarrado e açoitado. Todos da tripulação, mais os capitães e os imediatos dos dois navios assistem a tudo, em semicírculo, solenes. Algumas gotas de sangue voam (caindo na mão do amante de Hickey), o algoz hesita um pouco na força a ser aplicada, mas Crozier ordena que repita. Das trinta chibatadas, vinte e três são mostradas, em ritmo lento, para que o algoz possa usar o chicote com a força necessária. 0 silêncio da cena faz ressaltar os sons do navio, um navio de guerra todo em madeira rangendo, preso no gelo ártico. Podemos usar esse exemplo para pensar a discussão entre civilização, natureza bruta, organização humana e terror.

Podemos aqui expandir minimamente o que seja civilização, processo civilizatório e natureza, para que possamos discutir a unidade das ideias por trás das ações das personagens na série. A interpretação tentada aponta para a extrema influência de mentalidades que se consolidaram no século XIX. Podemos considerar duas definições de civilização, uma mais abertamente perceptível nos discursos, outra mais diáfana, voltada ao indivíduo. A segunda é retirada da pesquisa de Norbert Elias (1990) sobre o processo civilizatório radicado na individualidade. A primeira 
aparece na ingenuidade e normatividade de povos que se consideram portadores de verdades e de missões para, entre muitas aspas, "mudar o mundo":

Civilização, no sentido normativo de refinamento socialmente determinado, é então um conceito universal que não se limita à era moderna. Com frequência é associado à ideia de que o povo civilizado tem uma tarefa, ou mesmo um dever, de propagar seus valores culturais e seu modo de vida: seja para pacificar os bárbaros que vivem no mundo ao redor, para difundir a única doutrina verdadeira, ou simplesmente para fazer o que é bom. Tais motivos variados alimentam todos os tipos de "missão civilizadora" e abrangem mais do que apenas a disseminação de uma fé religiosa. (OSTERHAMMEL, 2009, p. 104)

Para Norbert Elias (1990), aqui interpretado por Jessé Souza (2000), a civilização aparece como estágio final, externo e individual (ao menos como exemplo que depois pode ser normatizado), como "a progressiva substituição do primado da violência por meios pacíficos na competição social pelos recursos escassos" (SOUZA, 2000, p. 48). A contraposição, ou o complemento, com toda nuance possível, pode ser feita à noção de natureza, bem como da relação entre os seres humanos e o mundo natural. Não inscrevo essa reflexão, portanto, na oposição entre "civilização" e "barbárie", nem priorizo essa dicotomia. Procuro não fazer menção a "barbárie" ao longo do texto exatamente por considerar esse conceito subsidiário ao de civilização, que por si só já não é bem definido (considerando que podemos entender civilização como um processo, não como um conceito unívoco). Aqui espelho a ideia de Michel Henry (2012), que inicia seu texto 
considerando que a barbárie "não é um começo. Ela sempre segue um estado de cultura que necessariamente a precede, e é apenas em relação a essa cultura anterior que ela pode aparecer, como algo empobrecido e degenerado"5 (HENRY, 2012, p. 5). Um avanço decisivo nessa área seria feito, segundo o autor, ao se pensar que, apesar da dificuldade teórica de definir as características da cultura e da barbárie, "e apesar da imprecisão e aproximação dos termos que a elas se referem, todos compreendem perfeitamente o que está em jogo"6 (HENRY, 2012, p. 95). Torna-se necessária então uma reflexão sobre a prática, de que a crítica a uma ideia imperfeita de civilização não leva necessariamente a um elogio à barbárie, ou a um fatalismo frente ao que se considera bárbaro. Como barbárie é o que a civilização não é, como é seu agon, seu oponente indefinido, aquele contra qual a "civilização" luta, escolho ver a fragilidade entre o discurso e a prática das ideias acerca do que é civilizado, de como esse horizonte (uma ideia a se tornar realidade, mas ainda não perpetrada) toma o centro da noção de que um país pode invadir, influenciar e dominar outras nações na medida em que se considera merecedor, onde as instituições levam os indivíduos a crer que podem impor sua visão de mundo aprendida e suas práticas a tudo aquilo que elas não são, a tudo aquilo que eles consideram "bárbaro". Fundamentalmente, não podemos chamar povos ou culturas de "bárbaros" porque nos falta definir o que é civilizado. As personagens em The Terror criam saber exatamente o que era civilização e cultura: era tudo

5 Tradução minha de "Barbarism is not a beginning. It is always second to a state of culture that necessarily precedes it, and it is only in relation to this prior culture that it can appear as an impoverishment and a degeneration".

6 Tradução minha de "in spite of the vagueness and approximation of the terms that refer to them, everyone understands perfectly what is at stake". 
o que o resto do mundo não era. Keith Thomas (1990), discute essa relação por outro meio, voltando-se à ideia de natureza contraposta à de civilização e cultura, em um período influente para as noções contemporâneas do processo: a Inglaterra entre 1500 e 1800, lugar e época que gestaram muitas das noções que herdamos de boas maneiras, hierarquia, ordem - em meio, claro, à brutalidade de um império em expansão comercial e militar.

Para Thomas, "um leitor que se aproximasse, inocente, dos escritos morais dos séculos XVI e XVII poderia ser perdoado por inferir que o principal propósito deles era definir a condição especial do homem e justificar seu domínio sobre as outras criaturas" (1990, p. 30). Essa distinção obstinada esconde e mostra a natureza monstruosa humana, criando uma mentalidade de submissão do ambiente que se fez central na criação da moderna ciência, a partir do lluminismo, e tornou invisível a dependência que nossa espécie tem do ambiente em que vivemos. "Na história conjetural que se foi tornando mais e mais popular devido ao Iluminismo europeu no século XVIII, fez-se da vitória do homem sobre as outras espécies o tema central" (THOMAS, 1990, p. 34). Além disso, a origem da sociedade humana "estava na associação dos homens para se defenderem das feras" (THOMAS, 1990, p. 34). Mais do que defesa, a civilização impediria que os homens se tornassem feras. Tal impedimento, no entanto, era levado a cabo de maneira violenta, causando terror, subjugando e agredindo quem se pensava agir em desacordo com as regras.

Uma vez percebidas como bestas, as pessoas eram passíveis de serem tratadas como tais. A ética da dominação humana removia os animais da esfera de 
preocupação do homem. Mas também legitimava os maus-tratos àqueles que supostamente viviam uma condição animal. (THOMAS, 1990, p. 53)

Não por acaso, portanto, a cena da punição de Hickey (o castigo aos outros dois marujos não é mostrado) é solene e grave, e acompanhada por capitães que não deixam transparecer o mínimo de satisfação no castigo: a punição para os infratores deve ser racionalmente aplicada, e deve servir de exemplo tanto para quem é castigado quanto para quem assiste - e todos devem assistir. Cria-se assim uma atmosfera de terror, de "sensação de espera" pelo fim do castigo, de algo que é "intangível e resiste a definição" (conforme a citação de Cavallaro (2002) acima). Tanto forma de incutir terror no presente, quanto um exemplo de que os feitos foram errados e em algum grau danosos, quanto exemplo de que não há satisfação animal em retribuição ou vingança, que se trata antes de corrigenda superior, uma forma de "perdão".

\section{NATUREZA E HORROR}

Incidentes e decisões do tipo citado acima estão em praticamente todos os momentos da série, e vão ganhando volume e concentração com o passar dos episódios. Após a punição de Hickey, o quinto episódio, "First Shot a Winner, Lads", é marcado por dois eventos: a possibilidade de a comida enlatada estar contaminada por chumbo, e um ataque de Tuun'aq ao navio ao final do episódio. Esse ataque ocorre durante uma discussão sobre o estado de saúde de Crozier, e de sua capacidade de tomar decisões acertadas. Após uma altercação, o imediato Thomas Blanky avisa Crozier: "Tome cuidado agora, ou o que aconteceu 
a John Ross na Praia de Fúria vai acontecer com você" (28:49). Veremos mais à frente que esse aviso indica um diálogo central tanto na criação do sentimento de horror cósmico. Esse aviso, assim como o ataque do monstro, tem a ver com o sentimento de selvageria causado pela incursão a ambientes extremos, e em como a natureza é considerada violenta para o "ser civilizado". Independentemente de a humanidade ter criado condições de subjugar a natureza, advindas do progresso técnico dos últimos séculos, esta ainda é considerada "boa" ou "má" conforme seja considerada domesticada:

Com efeito, embora pomares e bosques domésticos sempre tenham contado com a simpatia dos ingleses, a floresta fora considerada selvagem e hostil. Desde os tempos mesolíticos, o progresso humano dependeu de arrancar e destruir as árvores com que a maior parte da terra estava coberta. (THOMAS, 1990, p. 230)

Apesar de indicar apenas os ingleses no trecho acima, lembremos a influência que a Inglaterra vitoriana teve em nossa concepção ainda válida sobre o que é civilizado, em como esses valores foram voluntariamente aplicados no império ao longo do século XIX, em quantas nações influenciaram e o quanto ainda hoje são implicitamente validados. Apesar de toda divulgação, absolutamente correta, sobre a necessidade de entendimento e cuidado com o meio ambiente, da luta pela aplicação de ideias ecológicas e de sustentabilidade, nossa prática ainda é de descarte indiscriminado do lixo (vide as ilhas de plástico nos oceanos), produção desenfreada e irracional, afetando continuamente e em grau hediondo o frágil equilíbrio do ecossistema planetário 
(ver, por exemplo, LEWIS e MASLIN, 2015; ou RUDIMAN, 2013 sobre o antropoceno). A compreensão de nossa imersão na natureza e de nossa atuação nela ainda acaba sendo feita por especialistas, quando já deveria aparecer nas ações diárias e comuns: já falamos bastante sobre isso, mas ainda não fazemos na mesma medida. Nossa ideia prática ainda é a de subjugar a natureza. A impossibilidade de dominação talvez seja a causa do terror sentido por personagens que entram em um ambiente hostil, até o momento pouco enfatizado neste texto: o frio polar, com temperaturas extremas abaixo de zero e meses de noite contínua, onde a escuridão é branca, perpassada por um vento inacreditável. Um pequeno diálogo entre soldados do Terror, no mesmo episódio, faz referência ao monstro e ao clima. Eles estão soltando tiros de advertência no gelo (21:30), para indicar o local a um grupo que retorna ao navio, e um deles pergunta:

- E quanto à criatura, senhor? Se a gente pode ouvir o disparo do canhão de longe... não estamos chamando-a até nós o dia todo?

- Ou assustando-a. Estou com mais medo do frio, rapazes. Vou tocar o clavicórdio quando chegar em casa. Pra isso preciso de todos os dedos? (KAJGANICH et al. 21:42)

Essa atitude de desassombro em relação às forças da natureza, ainda que parcial, é comum a praticamente todas as personagens, com exceção de três: o capitão Crozier, o cirurgião Goodsir e Lady Silêncio, apelido dado à netsilik capturada. As atitudes do

7 Tradução minha de: "- What about the creature, sir? If you can hear the cannon fire so far... haven't we been calling it right to us all day?

- Or scaring it off. I'm more afeared of the cold, boys. I play the clavier back home. And for that you need every finger". 
comandante Franklin, por exemplo, foram semelhantes até em sua morte (episódio 3, "The Ladder"): ele fora visitar o destacamento que estava caçando o monstro, até então considerado um urso polar maior do que o normal. Estava para se despedir do grupo quando um dos soldados perguntou se ele não queria ficar mais um pouco; talvez ele mesmo pudesse matá-lo. Franklin, junto ao cirurgião Goodsir, fica e é o segundo a morrer, tendo uma perna decepada e sendo arrastado até o buraco onde estava o corpo do xamã netsilik e jogado lá dentro (outro feito que levará a tripulação a levar o monstro a uma categoria sobrenatural).

É claro, o frio não era menos mortal do que o monstro. Quando este ataca o Terror, é justamente o frio que causa as maiores dificuldades e impedimentos. Uma tempestade assola os navios encalhados no gelo, vento furioso com neve e neblina que torna impossível ver qualquer coisa a mais de dois metros. Não há mais mar, tudo virou uma terra sólida, branca e desolada. Esse confronto extremo, tanto com a natureza quanto com as feras, e como ele partilha características do horror cósmico, pode ser tematizado no ataque de Tuun'aq ao Terror. Já antecipo, no entanto, que tal partilha é parcial. Vejamos uma definição do termo, feita por Vivian Ralickas:

Horror cósmico - aquele medo e admiração que sentimos quando confrontados com fenômenos além da nossa compreensão, cujo alcance se estende para além do estreito campo dos assuntos humanos e que se vangloria de significado cósmico - compõe a expansão da imaginação do sujeito que o experiência. (2007, p. 364)

No caso presente, em The Terror, a primeira parte (medo e admiração pelo desconhecido) e a segunda (alcance além do campo 
dos assuntos humanos) se fazem presente; o significado cósmico não está. Talvez porque a aparição do monstro esteja no limiar da linguagem e de conhecimentos prévios para expressá-lo, dadas as discussões na tripulação sobre se o monstro seria um urso ou não.

O ataque se dá de forma súbita, mas inicia discretamente, a partir de 29:47 (episódio 5, "First Shot a Winner, Lads"). Não há o anúncio visual da fera, mas sim o aviso de uma sentinela, que chega antes dos gritos de um terceiro, avisando o imediato Blanky. Um dos guardas dispara na direção indicada por outro, mas a nevasca toma todo campo de visão. $\mathrm{O}$ tiro acerta uma espécie de coberta de proteção do convés, e uma das estacas dela fecha a saída principal do interior do navio, deixando praticamente toda a tripulação do Terror presa. A saída alternativa, na escotilha traseira, acabara de ser selada. Enquanto os guardas tentam arrombá-la e visualizar o monstro, a tripulação consegue ver que ele está indo para a popa (parte frontal) do navio. Os homens aguardam o monstro com mosquetes. Ele ataca um soldado e o atira para fora do navio, de surpresa. Esse trecho, por volta de 31:00, possibilitará pensarmos mais adiante em elementos de horror cósmico. Com a parte central do navio bloqueada, Blanky manda os guardas, agora sem munição, darem a volta até a proa por fora do navio e se esconderem, e encara a fera. Somente suas patas aparecem, descomunais mesmo para um urso polar. O olhar de Blanky mostra ao mesmo tempo medo e coragem, incrédulo talvez de encarar uma fera desconhecida. Blanky foge subindo para o mastro (e o ritmo de sua fuga, deliberado, quase sem pressa para uma situação tão perigosa, também indica esse embate entre o civilizado e brutal), até o alto, talvez esperando que Tuun'aq não suba, mas o monstro sobe, 
escalando o mastro. Blanky busca os acendedores dos lampiões, na esperança de que algum tenha querosene e um acendedor. Joga um desses, que não atinge o monstro mas mostra sua face. Até o momento, as descrições implicavam um urso polar, ainda mais na leitura dos exploradores árticos experientes: Franklin, Crozier e Blanky. No entanto, é um animal muito maior, com uma cabeça em nada semelhante a um urso. Na verdade, os traços de Tuun'aq estão entre caninos e humanos, e seu tamanho tem quase o dobro do de um urso polar. Também sua inteligência e capacidade física parecem sobrenaturais.

No convés, a tripulação conseguiu abrir a escotilha selada e agora prepara o canhão para atirar no monstro, mas não consegue ver nada devido à nevasca interminável. Nisso, Blanky consegue outro lampião, atira sobre o monstro e o pelo deste pega fogo, indicando a direção aos soldados. O canhão não é grande, sua espessura é semelhante à de um copo, mas é preciso deslocá-lo e ele está trancado no gelo. Um soldado pega no cano de metal sem usar luvas e consegue deslocar o canhão, mas sua pele fica inteiramente grudada no cano quando retira a mão (temos aqui a resposta narrativa ao diálogo acerca do cuidado com os dedos e mãos, clavicórdio e frio). Eles atiram, o monstro é atingido, tanto ele quanto Blanky caem do mastro. Blanky fica pendurado nas cordas, o monstro deixa um rastro de sangue. Blanky então é levado à cabine do Dr. McDonald. Tuun'aq rasgou sua panturrilha e a decisão é amputá-la. Dão whisky a Blanky (o capitão Crozier, que tem problemas com álcool, traz a bebida), mas ele pede que todos façam um brinde antes, ao 'noivado' entre ele e a fera. A perna é cortada em algumas passadas de serra e não é mostrada, o que 
intensifica o efeito ao concentrar a cena na dor e na consternação do grupo em vez de em sangue e vísceras.

Essa cena exemplifica graficamente o confronto entre o desejo de civilização e a natureza bruta, ambos inseridos no contexto da modernidade europeia imperialista e ainda expansionista do século XIX. Conforme dito no início da série, a intenção da expedição era encontrar a chamada "passagem noroeste" ao norte do Canadá (ainda território britânico à época) que levaria navios da Inglaterra diretamente à China e ao Japão, sem necessidade de circunavegar a África ou o sul do Oceano Índico. Era a segunda expedição à área, e fora lançada com otimismo e capitaneada pelo otimista John Franklin. Tinha tudo para dar errado (BEATTIE; GEIGER, 2014; DAVIS-FISCH, 2012), mas não nas mentes confiantes no império britânico, ingênuas a ponto de acreditar na submissão e passividade da natureza. Hoje é claro ver como eram inadequadas as tecnologias usadas na época: navios de madeira (por robustos que fossem), com motores a vapor adicionais que não funcionariam em temperaturas extremas; comida enlatada com chumbo nos lacres das latas, aos poucos adoecendo e enlouquecendo todos que a consumiam. Sem caça ou recursos vegetais de onde tirar comida na natureza, acabou-se por chegar ao último recurso de sobrevivência: canibalismo.

Tratemos desse tópico. Porém, importa primeiro pensar a noção ingênua de superioridade moral humana, já falível em condições normais, ainda mais quando imersa além de qualquer condição equilibrada de existência. Beattie e Geiger (2014) falam do ultraje da opinião pública britânica quando expedições de busca posteriores relataram ter encontrado indícios de 
canibalismo entre a tripulação do Terror e do Erebus. Eles citam John Rae, um dos expedicionários que procurou Franklin: "pelo estado mutilado de muitos dos cadáveres e do conteúdo das chaleiras, é evidente que nossos miseráveis compatriotas haviam sido levados ao último recurso - canibalismo - como meio de prolongar a existência" ${ }^{\prime 8}$ (RAE, 1855 apud BEATTIE; GEIGER, 2014, p. 113). As respostas a tal afirmação foram várias, instantâneas e ultrajadas. Segundo os autores, muitos se recusaram a crer que o canibalismo era possível. O escritor Charles Dickens, amigo da esposa de Franklin, argumentou a tripulação de Franklin era a fina-flor da marinha inglesa, e que "é improvável, no mais alto grau, que tais homens quisessem, ou pudessem, em qualquer extremo de inanição, aliviar as dores da fome por tal meio horrível"9 (DICKENS, 2005 ${ }^{10}$ ).

Shirley Lindenbaum (2004, p. 492) comenta que repensar a imagem do canibal oferece oportunidade para nos libertar da criação de "concepções sobre nós mesmos que dependem da difamação dos outros". Embora em nenhum ponto o autor do presente texto possa concordar com qualquer prática envolvendo consumo de carne (de nenhum ser) - e ao mesmo tempo defendendo o fim de toda concepção que se baseia em humilhação e mesmo em hierarquia -, a vida prática fornece exemplos diferentes de como os humanos tendem a proceder em situações extremas de fome e privação. Apesar de ficcionalizados,

8 Tradução minha de "From the mutilated state of many of the corpses and the contents of the kettles, it is evident that our wretched countrymen had been driven to the last resource - cannibalism - as a means of prolonging existence".

9 Tradução minha de "it is the highest degree improbable that such men would, or could, in any extremity of hunger, alleviate the pains of starvation by this horrible means".

10 Disponível em: http://www.victorianweb.org/authors/dickens/arctic/pva342.html. 
os eventos referentes ao canibalismo na série não estão longe de casos reais. A ficção menos inventa e mais rearranja o horror.

\section{OS ÚlTIMOS RECURSOS: MEDO, MORTE, CANIBALISMO}

Lindenbaum lista alguns tipos diferentes de canibalismo, e entre eles o canibalismo de sobrevivência: "o consumo de outros seres humanos quando em condições de fome, como naufrágio, cerco militar e fome, em que pessoas normalmente avessas à ideia são movidas a isso pela vontade de viver" (2004, p. 477). Em The Terror, as ideias gravitam mais e mais, conforme a situação das tripulações vai se agravando, em duas frentes: primeiro, morte e assassinato, e depois na ideia de consumir os mortos para se manter vivo.

No caso da narrativa, é exemplar um diálogo, no início do episódio 6, "A Mercy", entre o imediato Blanky e o capitão Fitzjames, do Erebus, logo após este ter a perna decepada. Fitzjames pergunta a Blanky o que ele quis dizer quando falou ao capitão Crozier que se não tomasse cuidado, o que acontecera a John Ross na Praia da Fúria também aconteceria a ele (Crozier). Blanky conta então de quando passou três invernos no navio Victory. "O capitão [John Ross] teria tentado um quarto [inverno] se a comida não tivesse acabado. Não devíamos ter esperado tanto para começar a caminhar. Quando começamos, já estávamos com escorbuto. E o Capitão Ross não tinha pena da doença" (03:30). Blanky diz ter implorado a John Ross para abandonar os barcos salva-vidas (que eles arrastavam por terra), "mas ele respondeu que preferia abandonar os doentes, para morrer [...] Foram 482 km até a Praia da Fúria. Quase não nos aguentávamos de pé. O pouco de amor que tínhamos uns pelos outros era o que 
mantinha a civilidade". Mesmo quando chegaram à Praia da Fúria, o capitão Ross manteve a hierarquia: "Os oficiais mantiveram seus camareiros e cobertas de pele de lobo, e todo salmão que conseguimos pescar". O diálogo continua:

- O resto dormia em valas de gelo e brigava por biscoitos do ano anterior. Depois que toda esperança se vai, a mente fica com... pensamentos anormais.

- Que tipo de pensamentos?

- Do tipo abrir a cabeça de Sir John Ross com um machado. O sr. disse que queria a verdade, com minhas próprias palavras. Confio que não vou passar por corte marcial por causa delas.

- Teria feito isso?

- ... As estradas abriram em agosto. Fomos pegos pelo [navio] Isabella. Éramos dados como mortos há dois anos.

-Sr. Blanky... A maior parte dos homens sobreviveu. - Se esse é o ponto em que deseja que eu chegue, senhor, então sim, sobrevivemos. Mas se quisermos sair daqui - e estamos quase três vezes mais longe - o senhor precisa entender que não foi a doença ou a fome o que mais pesou nas nossas chances. Foi o que aconteceu aqui [aponta para a cabeça]. Ideias. Uma escuridão... Sem mão para segurar o leme. Sei que muitos estavam pensando o mesmo que eu. Sir John Ross, ele nunca soube o quanto esteve próximo.

- Esse tipo de escuridão... Você a vê entre nós, aqui?

- Não preciso vê-la para saber que está aqui. ${ }^{11}$

11 Tradução minha de:

The rest of us just slept in ice ditches and fought over year-old biscuits. And once it's past all hope, the mind goes... unnatural with thoughts.

- What kind of thoughts?

- Like splitting open Sir John Ross's head with a boat axe. You said you wanted the truth, sir, in my own words. I trust you won't court martial me for them now.

- Would you have done it?

- Leads opened up in the August. We got picked up by the Isabella. We'd been taken for dead for two years. 
O diálogo entre Blanky e Fitzjames espelha e dá voz ao sentimento desenvolvido por toda a narrativa, de um medo cósmico: "uma experiência devastadora que desperta um medo muito maior do que o de simplesmente morrer"12 (RALICKAS, 2008, p. 297). Note-se que esse elemento tem seu lastro em eventos reais: a parte sobre a falta de humanidade de Ross ou os desejos secretos da tripulação são ficção, embora plausíveis no contexto; mas o relato é embasado na segunda expedição de Ross ao ártico (1832). Note-se também o embate entre a pulsão de sobreviver e a pressão injustificada de manutenção da hierarquia em meio a um contexto violentíssimo: arrastar por terra barcos lotados com provisões, por mais de $400 \mathrm{~km}$, e o desprezo da autoridade central da expedição em considerar as necessidades dos comandados. Mais uma vez é referida a subjugação dos impulsos (nesse caso, ter conforto e sobreviver) a uma instância considerada civilizada (hierarquia e autoridade). Se "o sono da razão produz monstros", como no quadro de Goya, a razão descontextualizada os desperta; descartar a razão leva ao medo e à ignorância; exacerbar a razão sem atentar às circunstâncias leva ao desastre; nesse caso, vale a afirmação que embasa o estudo do processo civilizatório: "Os homens são as suas circunstâncias e não existem fora delas" (SOUZA, 2000, p. 51).

- Mr. Blanky... most of the men survived.

- If that's the point you want me to get to, sir, then, yes, we survived. But if we're going to walk out of here ourselves - and almost three times as far - you need to understand it wasn't sickness or hunger that most mattered to our chances. It's what went on up here. Notions. A darkness... with no firm hand to stem it. I know many were thinking what I was. Sir John Ross, he never knew how close he came.

- This kind of darkness... do you see it among us here?

- I don't need to see it to know it's here.

12 Tradução de "a devastating experience which rouses a fear far exceeding that of merely dying". 
Esse embate continuará a ser travado até o final da temporada, aprofundando-se cada vez mais, com resultados desastrosos. No diálogo citado acima, Blanky propõe o retorno ao Sul a pé, o quanto antes, mas pede que Fitzjames, "se for esconder alguma coisa dos homens, dê a eles algo em troca. Agora. Algo para suas mentes focarem... que não seja o que vem por aí. Eles vão fazer um inventário de tudo quando as coisas ficarem difíceis. Sempre fazem" (07:04). Fitzjames decide então, celebrando o retorno do sol após meses de escuridão, fazer uma festa no gelo, com todo tipo de atração possível: música, dança, jogos, fogo, banhos, espetáculos.

Ainda no sexto episódio, em meio aos preparos, Collins, o mergulhador do Erebus, procura o médico para falar sobre o que sente: diz que está ficando com "pensamentos agitados" (20:00). Sente-se sozinho o tempo todo e procura executar qualquer tarefa que esteja à mão. $\mathrm{O}$ dr. McDonald despreza seu relato, sobriamente. Diz que a culpa é do inverno: Collins deve manter a esperança e procurar se divertir na festa. Collins sua frio em frente ao médico. Este volta a ser consultado, dessa vez pelo cirurgião Goodsir, que avisa sobre a morte do macaco de Franklin, com os mesmos sintomas da contaminação por chumbo (29:12). McDonald diz que vai falar com o capitão sobre isso, que a decisão de comunicar a descoberta de Goodsir é dele, McDonald. Goodsir insiste que ele o faça imediatamente, mas McDonald usa de sua autoridade e diz a Goodsir para não falar nada. McDonald está louco, mas não vemos isso ainda.

A festança corre relativamente bem, quando Crozier desperta de sua reabilitação: trancara-se na cabine por semanas 
para parar de beber. Vai até a festança e Fitzjames o avisa sobre - retorno a pé. Crozier pede a palavra e começa a discursar com a tripulação, noticiando a decisão, quando dois eventos se sucedem: primeiro, Lady Silêncio corta a própria língua e caminha até a festança, sangrando. Ela entra na grande tenda e cai no chão. Quando a estão socorrendo, o dr. McDonald entra na tenda e, usando a bebida altamente alcoólica da festa, toca fogo em si mesmo. Antes disso, ele havia espalhado a bebida ao redor da tenda e ateado fogo a tudo. Novamente vemos na atitude individual do médico o embate civilizatório: uma transformação da repressão externa (violência, castigos) em repressão interna (autocontrole, autocensura, superego) (SOUZA, 2000, p. 51). Nesse caso, no entanto, a repressão dos impulsos, especificamente o impulso de destruição frente a adversidades, escoou-se do sentimento para a ação. McDonald estava louco, mas portava-se dignamente, civilizadamente. Essa relação entre o comportamento reprimido externo e os impulsos internos está no cerne do processo civilizador, e cabe aqui pensar também que a ideia de civilização é normalmente vinculada à imagem de alguns países, não a todos nem a muitos: Alemanha, Inglaterra, França, alguns poucos mais; é de onde Elias (1990) tira seus exemplos mais constantes. Claro estar que se trata de um texto propagandeado, muito mais do que uma realidade uniforme. Mas é também uma ideia desenvolvida nesses lugares, na modernidade (embora a atitude civilizatória seja de todos os tempos nas nações poderosas, como Roma), uma ideia que pode ser facilmente usada para embasar um mito nacional, e que subentende diferenças. 
A palavra alemã Kultur, a equivalente nacional da palavra francesa civilization, possui, nesse sentido, um significado antes de tudo antitético em relação a essa última. Civilização na Alemanha denota um sentido negativo de "exterioridade", de algo enganoso e superficial, uma mera cortesia, a qual deve ser contraposta com o sentido das virtudes "verdadeiras". (SOUZA, 2000, p. 53)

Essa diferença entre cultivo interior e prática exterior conversa com os problemas de todas as nações que se engajam, ainda que sem clareza do objetivo, no processo civilizador. No caso do Brasil, país que recebe influxo cultural externo constante e que se embate em tal processo, seus sucessos, incoerências e paradoxos soam mais agudamente. Souza $(2000,2017)$ usa a pesquisa de Elias para pensar o processo civilizacional no contexto brasileiro. Segundo o autor, a sociedade brasileira tem a especificidade de ser formada a partir da escravidão como instituição, mantendo uma distinção hierárquica e não problematizada entre "gente" e "sub-gente" (para usar os termos do autor), apontando a semelhança entre formas sociais medievais e a formação brasileira.

Para Elias, apenas na passagem da baixa à alta Idade Média, ou melhor, na passagem da sociedade de cavaleiros guerreiros para a sociedade incipientemente cortesã, temos uma primeira forma de regulação externa significativa da conduta, ainda que estejamos muito longe do tipo de regulação interna exigida por uma sociedade industrial democrática moderna. A forma social anterior, no entanto, a sociedade guerreira medieval, como descrita por Elias, é em muitos aspectos semelhante à brasileira colonial como vista por Gilberto Freyre. Antes de tudo, pelo caráter autárquico do domínio senhorial 
condicionado pela ausência de instituições acima do senhor territorial imediato.

Uma tal organização societária, especialmente quando o domínio da classe dominante é exercido pela via direta da violência armada (como era o caso nos dois tipos de sociedade), não propicia a constituição de freios sociais ou individuais aos desejos primários de sexo, agressividade, concupiscência ou avidez. As emoções são vividas em suas reações extremas, são expressas diretamente, e a convivência de emoções contrárias em curto intervalo de tempo - como o assassinato seguido de culpa intensa - é um fato natural. (SOUZA, 2017, p. 48-49, grifo meu)

Note-se também, na citação, a referência à presença de uma única autoridade, exercida de maneira direta, recorrendo à violência como forma de gestão de controle e substituta do autocontrole necessário, quiçá presente em outros contextos que não o de fome, frio e escorbuto no meio do deserto ártico. Este papel, análogo na prática ao do senhor feudal e ao senhor de terras brasileiro (embora em outra escala e contexto), aqui é exercido pelos capitães, uma autoridade moral sem recurso superior. Outras instituições habitam o interior dos tripulantes, decerto (Deus, a ideia de família). Porém, o exercício da autoridade é feito pela mesma noção dos capitães como "centro", instância final de decisão sobre os destinos.

Assim temos que McDonald portava-se "civilizadamente", sem contudo interiorizar a civilização, ter cultura (no sentido alemão moderno). Comportava-se e se expressava de modo racional, mas pode ter considerado que, dada a situação extrema e desesperadora da expedição, com um dos capitães doente, melhor seria todos 
perecerem do que sofrer com a contaminação e um retorno impossível por terra. Novamente, sono da razão e racionalidade descontextualizada. O pandemônio na festança acaba em morte, desespero e escassez, dada a quantidade de recursos destruídos. A tripulação restante tem o moral cada vez mais abalado. Cresce nos integrantes o sentimento de medo, um medo cósmico que não vem só do desconhecido, mas também do que se conhece. No caso presente, um dos acontecimentos mais trágicos e arrepiantes da expedição (as evidências e os relatos de canibalismo) é usado na narrativa cruamente, mas também para dividir os "civilizados" (ou aqueles que chamam a sim mesmos de civilizados) e os "selvagens". A narrativa, até aqui matizada, sem tons heroicos, desenvolvese agora com menos tons de cinza, com uma divisão binária em sua parte final: um grupo de dissidentes que gravita ao redor do insolente marujo Hickey, rotineiramente desafiando Crozier e o status hierárquico, de um lado; do outro, o grupo liderado pelo próprio Crozier. Essa divisão acontece efetivamente após mais um ataque de Tuun'aq, no meio de um julgamento: Crozier está julgando Hickey, com pena de enforcamento, por este ter matado dois colegas, mais um grupo de esquimós. Novamente, Crozier usa a autoridade e a hierarquia para levar Hickey a julgamento, juntando provas contra ele. A chegada do monstro, em outra noite de nevoeiro, interrompe tudo e dá chance do grupo de seguidores de Hickey fugir, levando um barco com provisões preparado secretamente, e levando reféns úteis, como o cirurgião Goodsir.

O grupo de rebelados, com Hickey no comando, vai se utilizar do canibalismo como forma de subsistência. Isso acontece no episódio 9, intitulado "The $C$, the $C$, the open $C$ ". A referência 
é a um momento do episódio (45:26), quando o Dr. Bridgens lê um poema no diário do ten. Little, seu confidente, que está para morrer. O primeiro verso é "The sea, the sea, the open sea". A princípio, o jogo de palavras entre o poema e o título permanece opaco, mas a referência é ao canibalismo: the open $C$ = o C(anibalismo) aberto. Interessante também notar que, após os créditos inicias, há uma cena que mostra o ten. Hodgson, agora perdido após o ataque do monstro ao acampamento, sendo encontrado pelo grupo rebelde de Hickey. Hogsdon está comendo o couro de suas botas. A cena é uma referência novamente a John Franklin, comandante original da expedição, que recebeu o apelido de "The man who ate his boots" [0 homem que comeu suas botas], por ter feito isso durante uma expedição de mapeamento da costa norte do Canadá, além de ter usado sopa de líquen e outras soluções, para não precisar lançar mão do canibalismo ${ }^{13}$. Dessa vez, no entanto, não são as botas o recurso. A divisão entre grupo oficial e grupo rebelado, é indicada não mais pela rebeldia e astúcia de Hickey, mas por usar a carne humana como alimento. Apesar da necessidade e da fome constante, são a rebeldia e a arrogância de Hickey que o levam ao motim.

E o primeiro a ser consumido é o próprio amante de Hickey, Billy Gibson, que se queixa de dores a Goodsir (episódio 9, 12:44). Este, já ciente de que se trata de envenenamento por chumbo, acumulado no corpo ao longo de anos, avisa Hickey sobre o destino de Gibson. Hickey sai de cena. Em meio à conversa de Goodsir e

13 Ver http://www.bbc.co.uk/ahistoryoftheworld/objects/hYm6Rg2dTri7iHrT2iJTtw. Também BRAND, 2010. 
Gibson, Hickey entra de súbito com a pequena faca que sempre carrega. Hickey apunhala Gibson repetidas vezes nas costas (outro tropo do "incivilizado", dessa vez em metáfora visual: o traidor). O choque de Goodsir, que está no grupo porque foi sequestrado e é uma das figuras civilizadas, indica novamente o horror e a abjeção ao ato que considera irracional, a incompreensão frente a violência e à crueldade. Hickey ordena que Goodsir corte os melhores pedaços de Gibson. Este se recusa, mas Hickey ameaça matar outro homem a cada hora, caso Goodsir não o faça. Aparece então, em Hickey (mais do que em seu grupo de rebelados), a vitória da não-civilização, da brutalidade. Assim como ameaçou outros caso Goodsir não cortasse os pedaços, na prática subjugando-o, matou seu amante menos pela necessidade de carne do que pelo que considerava clemência. Adiante veremos que, pelo menos em The Terror, essa brutalidade não será equalizada à natureza.

No último episódio da temporada (10, "We Are Gone"), vemos escalar ainda mais a brutalidade e a morte. Usando de um ardil, o grupo de Hickey captura o capitão Crozier. No acampamento desse grupo, ele encontra Goodsir. Ao se despedirem, Goodsir, diz a Crozier:

- Se o sr. ainda estiver no acampamento quando eu virar refeição, por honra, Capitão, não aceite. Se ele insistir...

- Não vamos deixar chegar a tanto.

- Se ele insistir, coma apenas meus pés. O senhor entendeu? Meus pés. As solas, se possível. A parte mais dura. Entendeu? Tudo depende disso. ${ }^{14}$ (THE TERROR, 10:45)

14 Tradução minha de:

- If you're still in the camp when a meal is made out of me, honor bright, Captain, do not accept. If he insists...

- We won't let it come to that. 
Feito isso, durante a noite, Goodsir prepara uma infusão venenosa e passa pelo corpo, exceto nas solas dos pés, cortando os pulsos em seguida. Na manhã seguinte, Crozier acorda com os homens já tendo cortado os antebraços e as coxas de Goodsir, e o estão comendo. O cadáver está deitado de bruços, quase ao lado da mesa. Hickey ordena que Crozier coma um pedaço. Relutante, Crozier levanta, corta um pedaço da sola do pé de Goodsir e mastiga. Matando-se e envenenando sua pele e carne, Goodsir envenena e mata a todos. Segue-se talvez o diálogo mais exemplar do embate que abrange civilização, domínio, cultura e brutalidade, entre Hickey e Crozier. Com "modos ingleses", tom respeitoso e ponderado, trava-se o seguinte diálogo:

- Vamos nos instalar para uma soneca em breve. Mas... venha, sente-se por um momento, Sr. Crozier. Eu estava ansioso por isso.

- Por que não deixar o Tenente Hodgson voltar? Ele e alguns homens de volta ao outro acampamento, ele poderia liderá-los. Sr. Diggle, Dr. Goodsir, Manson. Eles poderiam acompanhar o Tenente Hodgson.

- Ele foi o primeiro de seus oficiais que recrutei. Lembro do dia. Ele estava com uma pata de cachorro na mão.

- Bem, eu o perdoo. Perdoo a todos eles... menos você.

- O sr. se inclui nesse perdão?

- Não vou saber até isso terminar.

- O sr. se apega ao padrão de um homem que não é... nem nunca deveria ter tentado ser. Deixou que a vergonha o levasse sempre adiante. É parte do motivo de estarmos onde estamos.

- If he insists, eat only of my feet. Do you understand? My feet. The soles, if possible. The toughest part. Do you understand? Everything depends on this. 
- Então por que me trouxeram aqui? Um grande risco para seus homens.

- Tuunbaq [Tuun'aq]. Um espírito que se veste de animal. No entanto, nós atiramos nele com um canhão e derramamos sangue. Como o sr. concilia isso?

- Não sei. Há muito sobre esta viagem que não consigo conciliar.

- A que mitologia esta criatura pertence?

- Sobre a criatura, não tenho respostas, Sr. Hickey. Não era para nós sabermos disso.

- Eu não tinha ninguém a minha altura nesta expedição... exceto o sr.. Queria lhe agradecer por isso. Na véspera de um dia muito importante.

- Você deve ser um homem extremamente solitário, Sr. Hickey.

- Não por muito tempo ${ }^{15}$.

\section{Passamos da tentativa de negociação de libertar os reféns civilizadamente para a astúcia de Hickey (que conquistou}

15 Tradução minha de:

$\mathrm{H}-$ We'll be settling down for sick nap soon. But... come and sit for a moment, Mr. Crozier. I've been looking forward to this.

C - Why not let Lieutenant Hodgson go back? He's some men back at the other camp who could use his leadership. Mr. Diggle, Dr. Goodsir, Manson. They could accompany Lieutenant Hodgson.

$\mathrm{H}-\mathrm{He}$ was the first of your officers I enlisted. I remember the day. He had a dog leg in his hand.

C - Well, I forgive him. I forgive all of them... but you.

$\mathrm{H}-$ Do you include yourself in that forgiveness?

$\mathrm{C}-$ I won't know until the end of this.

$\mathrm{H}$ - You hold yourself to the standard of a man you are not... nor should ever have tried to be. You've let shame drive you on and on. It's part of why we are where we are.

$\mathrm{C}-$ Then why have me brought here at all? At great risk to your men.

$\mathrm{H}$ - Tuunbaq. A spirit that dresses as an animal. Yet we shot it with a cannon and drew blood. How do you reconcile that?

$\mathrm{C}-$ I can't. There's much about this voyage I can't reconcile.

$\mathrm{H}-$ What mythology is this creature at the center of?

$\mathrm{C}$ - About the creature I have no answers, Mr. Hickey. We were not meant to know of it.

$\mathrm{H}-$ I didn't have anywhere near an equal on this expedition... but you. I wanted to thank

you for that. On the eve of what is quite an important day.

C - You must be a surpassingly lonely man... Mr. Hickey.

$\mathrm{H}-$ Not for long. 
Hodgson oferecendo carne de cachorro a um faminto), ao perdão civilizado a todos, menos a Hickey, à defesa retórica deste, até a fala sobre tentar ser quem não é "nem nunca deveria ter tentado ser". Aparece então o motivo da amotinação de Hickey: Tunn'aq. Hickey, pelas falas, julga-se acima dos demais (busca verbalmente a igualdade com Crozier, uma autoridade) e quer se encontrar com a criatura. Antecipando esse encontro, Hickey refere-se à "véspera de um encontro importante". Efetivamente, o grupo rebelado encontra o monstro Tuun'aq, nessa ilha composta somente por pedras brancas, sem vegetação alguma ou mesmo sem elevações. Os soldados amotinados, que ainda portavam armas, gritam dizendo que avistaram o monstro e se preparam para atirar. A tensão na cena é criada pela espera de um perigo que está se aproximando, plenamente visível, mas do qual é impossível escapar. Essa inexorabilidade do confronto leva ao medo, não da surpresa de algo escondido, mas do que se mostra e que, sendo conhecido, mesmo assim não consegue ser impedido. Distingue-se então essa relação entre susto e medo. Em uma época em que produções midiáticas usam repetidamente a surpresa como dispositivo narrativo, The Terror faz do parcialmente conhecido a fonte de medo (em lugar do desconhecido ou do obscuro):

A ansiedade, medo e susto devem ser distinguidos na etiologia das neuroses traumáticas. A ansiedade é um estado particular de esperar o perigo ou preparar-se para ele, ainda que seja desconhecido. 0 medo exige um objeto definido do qual se tenha temor. Susto, contudo, é o nome que damos ao estado que alguém fica após entrar em perigo sem estar preparado para ele, dando 
ênfase ao fator surpresa. (MESHULAM-WEREBE, ANDRADE; DELOUYA, 2003, p. 39, grifo meu)

Assim o susto tem a ver com surpresas, o medo com o sentimento de temor. Embora hoje o primeiro seja usado para tentar provocar o segundo, a série a meu ver acerta de modo incrível ao causar medo, ao menos nas personagens, com elementos e acontecimentos que são vez mais conhecidos com o passar dos episódios, mas não menos perigosos ou humanizados. Em vez do tropo comum da escuridão, que associa tons escuros a selvageria e a animalidade, à baixeza e ao mal (CAVALLARO, 2002, p. 22), os elementos ambientais e naturais são todos brancos. Mesmo a escuridão é branca, em meio a nevascas, mares congelados e monstros de pelo albino. Escuros apenas os casacos dos tripulantes, os navios e o sangue que mancha a neve. Não há necessariamente uma desconstrução dos elementos do terror ou do horror; eles são suscitados por acontecimentos que escalam à luz do dia, mas nem por isso são esclarecidos; a direção soube trabalhá-los focando nas atuações e nas reações das personagens (como na surpresa e no horror de Goodsir ao ver Hickey apunhalar o amante e mandar cortá-lo) em vez de em efeitos visuais ou em monstros.

O encontro final entre Hickey, Crozier e Tuun'aq expõe, afinal, a fragilidade tanto de uma ideia de civilização alheia ao contexto quanto da falsa ideia que a brutalidade humana pode se equiparar à dos animais ou da natureza. Tuun'aq ataca e mata alguns dos homens. O grupo estava parado pois todos começaram a sentir os efeitos do veneno que Goodsir espalhara na própria pele, e cuja carne fora comida por todos ali, menos Crozier. À medida 
que os homens fogem e são caçados pelo monstro, Hickey, soberbo em cima do barco com mantimentos, repete uma ação feita pelos netsilik: oferecer a própria língua, cortada por si mesmo, a Tuun'aq, para com ele ter um elo espiritual, ato que tanto Lady Silêncio quanto seu pai (o xamã morto no início da temporada) fizeram. Tuun'aq mata todos até o momento, menos Hickey e Crozier, que se manteve imóvel, apesar de assustado. Hickey corta a própria língua e oferece a Tuun'aq. Este reconhece o gesto, para e cheira a mão de Hickey, para em seguida arrancála, junto ao braço. A surpresa nos olhos de Hickey expressam esse sentimento de traição e, afinal, horror: acreditava-se capaz de oferecer sua alma e tornar-se igual a Tuun'aq, mas este não mostra respeito pelo gesto (como fizera com Lady Silêncio e com seu pai), e castiga a soberba de Hickey, partindo-o ao meio e o devorando. Por já estar muito ferido dos ataques anteriores, e por ingerir o potente veneno da carne de Goodsir, além de expressivamente se engasgar com a metade do corpo de Hickey, Tuun'aq morre, não sem antes quase arrastar Crozier para dentro de sua boca, puxando-o pelas correntes.

O destino do monstro (termo principal usado pelas personagens) conversa com as sete teses sobre o tema elaboradas por J. J. Cohen: (i) o corpo do monstro é um corpo cultural; (ii) o monstro escapa sempre; (iii) o monstro é o prenúncio da crise de categorias; (iv) o monstro habita as portas da diferença; (v) o monstro policia as fronteiras do possível; (vi) o medo do monstro é na verdade um tipo de desejo; (vii) o monstro está no limiar... do vir-a-ser ${ }^{16}$ (1996, p. 3-25). Apesar de o corpo de Tuun'aq realmente 
ser visto como o absoluto outro e, nesse sentido, incorporar, "medo, desejo, ansiedade e fantasia", e de o monstro existir "para ser lido" (COHEN, 1996, p. 4), seu destino não é escapar, mas morrer sufocado nas fezes e no veneno que enche o corpo dos homens que mata. Apesar de o monstro "tornar-se imaterial e desaparecer, para reaparecer em outro lugar" (COHEN, 1996, p. 4), na narrativa ele não reaparecerá fisicamente. Sua morte definitiva, assim como o constante retorno padrão e mesmo clichê dos monstros, deve ser examinada "na matriz intricada de relações (sociais, culturais e histórico-literárias)" (COHEN, 1996, p. 5) que os geram. No caso presente, a morte do monstro se torna uma metáfora de traço romântico, porém fora do tropo da domesticação da mesma: a morte da natureza bruta, sem nenhuma glória para seus algozes, que morrem ao enfrentá-la, ao fugir dela ou ao querer com ela comungar a partir de uma posição de arrogância.

Resgatado por Lady Silêncio, Crozier acaba por escolher ficar com os netsilik, escondendo-se das expedições posteriores que foram tentar encontrar Franklin e os navios. Crozier pode ter escolhido ficar com o povo que considerava civilizado, o que aprendeu a conviver com seu ambiente sem danificá-lo, sem considerar que era o dono ou senhor da terra. Essa ideia, de que a natureza é algo a ser dominado e subjugado, é basilar em nossa cultura ocidental. Segundo Thomas, a domesticação dos animais tornou-se o padrão para a subordinação social no

the monster always escapes; (iii) the monster is the harbinger of category crisis; (iv) the monster dwells at the gates of difference, (v) the monster polices the borders of the possible; (vi) fear of the monster is really a kind of desire; (vii) the monster stands at the threshold... of becoming. 
ocidente: "o modelo básico era paternal, com o governante como bom pastor, tal como o bispo com seu rebanho. Animais dóceis e fiéis obedecendo a um senhor atencioso constituíam um exemplo para todos os subalternos" (1990, p. 55). Levada a extremos, essa domesticação/subjugação acaba sendo incapaz de atingir algum equilíbrio com o ambiente, em vez disso destruindo-o e forçando-o a revidar, seja na forma de um monstro, seja pelos próprios elementos, mas principalmente na forma da própria ignorância dos expedicionários, que julgavam sua força civilizadora capaz de domar a natureza com base na coragem em vez de no respeito ao ambiente onde se adentra. Claro, tal atitude ainda não foi modificada na essência, apesar do volume de conhecimento cada vez maior sobre a influência das ações humanas no clima planetário e da constância midiática sobre a necessidade de mudança nos padrões de comportamento humano.

\section{CONSIDERAÇÕES FINAIS}

Outros eventos e situações em The Terror ecoam as discussões sobre o que é civilizado, o que é brutal, o que é natural e animal. Com os exemplos discutidos acima, espero ter chamado a atenção à discussão acerca da ideia do processo de civilização, necessariamente criticando seus usos ingênuos (especialmente quando mal intencionados), sem necessariamente abandoná-lo ou, pelo menos, atentando para a necessidade de substituir uma mentalidade de dominação por uma de convivência. Exemplarmente, na série, toda a tripulação morre, exceto Crozier, que, mesmo tendo a mão arrancada por Lady Silêncio, para soltá-lo das correntes, decide ficar com o grupo netsilik, mesmo 
se deparando com um grupo de resgate inglês - Crozier está vestido como um netsilik e se afasta, misturando-se aos locais. Escolheu ficar com um grupo que compreende o ambiente, seu impacto na vida, e busca nele a harmonia em vez da subjugação, o entendimento em vez do mando ou da hierarquia sem contexto. Retomando as ideias iniciais, considerei o processo civilizador como o que tem em seu horizonte o orgulho ocidental, a supressão organizada da animalidade (sexo, catarse, raiva, medo); a busca por autocontrole, a exclusão da animalidade e a estabilidade; a conquista da natureza, domínio. Na série como um todo, e desse modo nos exemplos, o ingênuo orgulho civilizador leva à ruína da expedição; a supressão da animalidade e a busca por autocontrole deixa de funcionar no contexto extremo e alienígena do ártico, seja nos castigos exemplares, na tecnologia material inadequada; a natureza não humana não se deixa conquistar, morrendo envenenada e suja de excrementos humanos. Dada a continuidade desse tipo de ideia de civilização na sociedade global atual (apesar dos discursos em contrário, as ações ainda reafirmam a ideia de civilização por dominação), continuaremos passando pelo horror e medo cósmico, de um mundo/ambiente que desconhecemos porque estamos confortáveis e nos cremos certos, apesar dos vários tipos diferentes de monstros que nos perseguem.

\section{REFERÊNCIAS}

ARCTIC Tomb. Direção de Nigel Turner. Nova York: History Channel, 2001. 1 DVD (67 min.). Available at: https://www.youtube.com/watch?v=j94t4tN1w0\&t=2510s. Accessed on: $1^{\text {st }}$ Feb. 2021.

BEATTIE, Owen; GEIGER, John. Frozen in time: the fate of the Franklin expedition. Vancouver: Greystone Books, 2014. 
BRANDT, Anthony. The man who ate his boots: the tragic history of the search for the northwest passage. Nova York: Random House, 2010.

CAVALLARO, Dani. The Gothic Vision: Three Centuries of Horror, Terror and Fear. Londres; Nova York: Continuum, 2002.

COHEN, Jeffrey Jerome. Monster Theory: reading culture. Minneapolis; Londres: University of Minnesota Press, 1996.

DAVIS-FISCH, Heather. Loss and Cultural Remains in Performance: The Ghosts of the Franklin Expedition. Nova York: Palgrave Macmillan, 2012.

DICKENS, Charles. The Lost Arctic Voyagers (1854). The Victorian Web, mar, 2005. Available at: http://www.victorianweb.org/authors/dickens/arctic/ pva342.html. Accessed on: 15 th Feb. 2021.

ELIAS, Norbert. O processo civilizador (2 volumes). Tradução de Ruy Jungman. Rio de Janeiro: Zahar, 1990.

HENRY, Michel. Barbarism. Londres; Nova York; Continuum International Publishing Group, 2012.

LEWIS, Simon L.; MASLIN, Mark A. Defining the anthropocene. Nature, v. 519, n. 7542, p. 171-180, 2015.

LINDENBAUM, Shirley. Thinking about cannibalism. Annu. Rev. Anthropol, v. 33, p. 475-498, 2004.

MESHULAM-WEREBE, Daniela; ANDRADE, Mariana Gonzalez de Oliveira; DELOUYA, Daniel. Transtorno de estresse pós-traumático: o enfoque psicanalítico. Brazilian Journal of Psychiatry, v. 25, p. 37-40, 2003.

OFFICER, Charles; PAGE, Jake. A fabulous kingdom: the exploration of the Arctic. Oxford: Oxford University Press, 2012.

OSTERHAMMEL, Jürgen. The transformation of the World: a global history of the nineteenth century. Tradução para o inglês de Patrick Camiller. Princeton e Oxfford: Princeton University Press, 2009.

POTTER, Russell. Franklin Expedition Documentaries. In: POTTER, Russell. Visions of the north: the terrors of the frozen zone, past and present. 4 May 2018. Available at: https://visionsnorth.blogspot.com/2018/05/franklinexpedition-documentaries.html. 
PUNTER, D. Verbete 'Terror'. In: MULVEY-ROBERTS, M. (Org.). The Handbook to Gothic Literature. Londres: Macmillan, 1998.

RAE, John. Arctic exploration, with information respecting Sir John Franklin's missing party. Journal of the Royal Geographical Society, Londres, v. 25, p. 246$56,1855$.

RALICKAS, Vivian. "Cosmic horror" and the question of the sublime in Lovecraft. Journal of the Fantastic in the Arts, Idaho, v. 18, n. 3, 2007. RALICKAS, Vivian. Art, Cosmic Horror, and the Fetishizing Gaze in the Fiction of HP Lovecraft. Journal of the Fantastic in the Arts, Idaho, v. 19, n. 3, p. 297-316, 2008. RUDDIMAN, William F. The anthropocene. Annual Review of Earth and Planetary Sciences, v. 41, p. 45-68, 2013. Available at: 10.1146/annurevearth-050212-123944. Accessed on: 15 ${ }^{\text {th }}$ Feb. 2021.

SOUZA, Jessé. A modernização seletiva. Uma reinterpretação do dilema brasileiro. Brasília: Editora Universidade de Brasília, 2000.

SOUZA, Jessé. A elite do atraso: da escravidão à Lava-Jato. Rio de Janeiro: Leya, 2017.

THE TERROR. Direção de David Kajganich et al. Nova York: AMC, 2018.

Disponível em: https://www.primevideo.com/. Acesso em: 15 fev. 2021. THOMAS, Keith. O homem e o mundo natural. Tradução de José Roberto Martins Filho. São Paulo: Companhia das Letras, 1988. 